\title{
소방시설관리업 종사자의 직무스트레스와 이직의도의 관계 Relationship between Job Stress and Turnover Intention of Fire Protection System Management Workers
}

\author{
임경연* · 공하성** \\ Lim, Kyoung-Yeon*, and Kong, Ha-Sung**
}

\begin{abstract}
This study focuses on job stress, which may be the cause of the high turnover rate of fire protection system management workers, to demonstrate the influence of job stress on turnover intention. This research was conducted to confirm this correlation and utilize the obtained data for continuous employment. In this study, 354 fire protection system management workers were surveyed and factor analysis, correlation analysis, one-way ANOVA, and regression analysis were conducted using SPSS WIN 25. The analysis results are as follows: first, job stress did not differ with respect to age, education level, or monthly salary among sociological background causes. However, there were significant differences in position, total career, certificate difference, and tasks. Second, as job stress increased, the turnover intention was positively affected. In particular, the analysis showed that increased stress on "Organizational Systems" and a "Lack of Reward" led to high turnover intention. Therefore, it is necessary to introduce a reasonable management system, provide smooth organizational support, establish a channel for rational communication, prepare measures to induce internal motivation, develop technology, support self-development, and apply reasonable monetary compensation standards and applications to minimize these rates.
\end{abstract}

Key words : Job Stress, Turnover Intention, Fire Protection System Management Business, Fire Protection System Management Worker, SPSS

\section{요 지}

이 연구는 소방시설관리업 종사자의 이직요인일 수 있는 직무스트레스에 관심을 가지고, 직무스트레스가 이직의도에 미치는 영향을 실증 분석하고자 하였다. 이들의 상관관계를 확인하고 지속적인 고용을 위한 자료로 활용할 목적으로 연구 하였다. 이 연구에서는 소방시설관리업종사자 354명을 대상으로 설문조사를 실시하였고, SPSS WIN25를 이용하여 요인분석, 상관관계분 석, 일원분산분석 및 회귀분석을 실시하였다. 분석결과는 다음과 같다. 첫째, 일원배치분산분석에서 직무스트레스는 사회과학적 배경원인 중에서 연령, 교육수준, 월 급여에 대하여는 차이가 없으나, 직급, 총 경력, 자격증의 차이, 직무에 대하여는 유의미한 차이가 있다. 둘째, 직무 스트레스가 증가함에 따라 이직의도는 정(+)의 영향을 받는다. 특히, '조직체계'와 '보상부적절'에 대한 스트레스 증가는 이직으로 연결됨을 분석을 통해 알 수 있었다. 따라서 이러한 문제 해결을 위해서는 합리적인 경영시스템의 도입, 원활한 조직지원, 합리적 의사소통의 창구 마련, 내적동기 유발방안 마련, 기술개발과 자기계발 지원, 합리적 금전보상 기준과 적용이 필요하다.

핵심용어 : 직무스트레스, 이직의도, 소방시설관리업, 소방시설관리사, SPSS

\section{1. 서 론}

현대의 건축물은 산업발달로 인하여 대형화, 첨단화, 정보
화, 고도화, 심층화되고 있다. 또한 각종 신종산업은 다양화 되는 추세이며, 다중이용시설도 급속도로 늘어나고 있는 실정이다. 이런 시설에서 화재 발생 시 대규모 인명피해와

*정회원, 우석대학교 소방방재학과 박사과정(E-mail: soiosuns@hanmail.net)

Member, Ph.D. Candidate, Department of Fire and Disaster Prevention, Woosuk University

**교신저자, 정회원, 우석대학교 소방방재학과 교수(Tel: +82-63-290-1686, Fax: +82-63-290-1478, E-mail: 119wsu@naver.com)

Corresponding Author, Member, Professor, Department of Fire and Disaster Prevention, Woosuk University 
재산피해로 이어 질수 있기 때문에 평상시 소방시설의 유지 관리와 철저한 예방업무가 필요하다. 소방관서의 화재 방지 를 위한 소방검사 제도는 예방업무의 한 과정으로 순수공공 재의 성격을 가지며 화재예방과 예방소방정책에 크게 이바 지 하였다. 그러나 소방관서에서 증가하는 대형건축물과 선진화된 소방시설을 제한된 인력으로 전국의 소방대상물 에 대한 정밀검사실시는 한계가 있다.

자체점검제도가 도입되게 된 배경에는 관계인이 소방대 상물에 대하여 직접 책임지고 관리해야 한다는 자율적. 예방적 소방관리유도 측면과 정부주도하의 소방검사의 현 실적 문제점 극복, 전문 소방 검사 전문 인력의 양성 및 투입으로 실효성 있는 화재 예방정책의 실현에 있다고 할 수 있다. 소방시설관리업과 관련한 논문을 살펴보면, E.J. Park (2019)은 소방점검공영제 도입에 대한 연구를, Moon (2019)은 소방시설관리사의 행정처분에 대한 벌점제도입, 행정처분의 세분화, 안전관리업무 범위의 개선, 자체점검결 과보고서의 제출방식 개선 등 소방시설관리업 제도개선 연구하였고, J.H. Park (2019)은 소방엔진펌프 기동에 대한 신뢰성 연구 등 소방시설에 대한 연구를, Choi (2015)는 안전관리개선에 대한 연구 등의 범주에서 많은 연구가 진행 되어 왔다.

그러나, 소방시설관리업은 본질적으로 기술용역을 제공 하는 업종으로 기술 인력에 대하여 관심을 기울여야 한다. 따라서 소방시설관리업의 성장 발전을 위하여 필수요소인 기술 인력의 직무스트레스에 관심을 기울여야 한다. 타 분야에서는 스트레스 연구가 활발하게 진행되고, 스트레스 고 위험군인 소방공무원에 대하여는 많은 연구가 있다. 선행연구로는 Lee and Kim (2017)은 소방공무원의 직무스 트레스와 자아탄력성에서 소진의 영향을 연구하였고, Ryu (2013)와 Choi and Kim (2011)은 소방관의 직무스트레스와 직무만족을 다루었다. Chae et al. (2012)은 소방관의 직무스 트레스에 영향을 주는 요인을 검증하였고, Roe (2005)는 직무스트레스의 유발원인에 대하여 다루었고, Kim (2017) 은 소방공무원의 스트레스와 삶의 만족에 대하여 연구하였 다. Kim (2018)은 소방공무원에 대하여 직무스트레스와 직무만족에 대한 이직의도의 관계를 연구하였고, Lee (2007) 는 직무스트레스와 조직몰입에 대하여 연구하였다. 직무스 트레스가 이직의도의 미치는 영향을 Yun (2009)은 간호사 에 대하여, Lee (2004)는 경호원에 대하여, Ko (2008)은 미용종사자에 대하여, Ko (2018)은 주얼리산업 종사자에 대하여, Park (2016)는 교정직공무원에 대하여, Kim (2010) 은 유소년 종사자에 대하여, Kim (2005)은 호텔종사자에 대하여, Bae (2019)은 작업치료사에 대하여, Won (2018)은 직업무용수에 대하여, $\operatorname{Lim}$ (2007)은 보육교사에 대하여, Shim (2010)는 교육행정 및 기능직 공무원에 대하여, Cho (2013)은 소방산업 종사자에 대하여, Yang (2010)은 중소기 업직원에 대하여 연구하였다. 그러나 소방시설관리업 종사
자에 대한 연구는 전무한 실정이다.

소방청(National Fire Agency) 통계1)에 따르면 소방시설 관리업 기술자의 잦은 이직으로 높은 기술력 축적 곤란, 안전대행 소방시설물의 지속적 유지관리 곤란, 우수 인력수 급의 어려움 등이 있는 것으로 나타났다. 또한, 이직은 유능 한 근로자의 이탈로 신규 기술자의 모집, 채용 및 훈련의 비용증가 등 부정적인 영향을 끼치는 점에 주목하여, Kang (2015)은 계획된 행동이론에서 행동을 예측하는 가장 중요 한 변수인 이직의도를 파악하여 조직의 입장에서 구성원의 이탈방지를 위한 긍정적인 요소의 유인과 부정적인 요인을 감소시킬 필요가 있고 하였다. 이 연구에서는 이러한 관점에 서 직무스트레스와 이직의도의 상관관계를 확인하고 지속 적인 고용을 위한 자료로 활용하기 위한 목적으로 연구를 하였다. 또한 이 연구는 Lim and Kong (2019a)의 소방시설관 리업 종사자의 직무스트레스와 직무만족의 영향 연구, Lim and Kong (2019b)의 소방시설관리업 종사자 직무만족과 이직의도와의 관계 연구와 같은 연결선상의 후속 연구이다.

\section{2. 이론적 고찰}

\section{1 소방시설관리업}

재난관리의 4단계는 예방(Mitigation Management Stage), 대비(Preparedness Stage), 대응(Response Stage), 복구단계 (Recovery Stage)로 구분될 수 있다. 이중 예방과 대응 단계는 재난을 최소화하는 안전체계의 중요한 축이라 할 수 있다. 화재 예방행정의 경우, 순수공공재와 민간재의 혼합으로 구성되어 있는데 국가소방서비스로 소방특별조사가 있다 면 관주도의 소방검사를 탈피하여 관계인의 화재대응능력 을 제고하기 위하여 민간재로 소방시설 자체점검제도를 두고 있다. 이와 같은 업무를 실현하기 위하여 만든 업종이 소방시설관리업이다. 소방시설관리업의 업무를 소방안전 관리 업무의 대행 또는 소방시설 등의 점검 및 유지· 관리로 법규에 규정하고 있다.

\section{2 소방시설관리업 현황 및 종사자}

소방시설관리업은 소방청 '2018년 소방산업통계집'을 분석하면, 전 소방산업의 매출액과 종사자 수는 15 조 5,614 억 원과 16 만 1,318 명이고 소방시설관리업의 매출액과 매출 비중, 종업원 수와 그 비중을 보면 매출 5,483 억 원, 비중 $3.5 \%$, 종업원의 수는 6,561 명, 비중은 $4.1 \%$ 를 차지한다. 소방시설관리업의 기본현황의 변화 추이를 분석하고자 소 방산업통계기준이 정립되기 시작한 2012년부터 2017년까 지의 6개년 자료를 바탕으로 살펴보면, 소방시설관리업체 수에서 2012년도 기준 345개소에서 2017년 423개소로 매년 $4.1 \%$ 의 증가세를 보이며 포화상태 양상을 보이고 있다.

1) 2018년 소방산업통계집 pp. 28-32. 
소방시설관리업종사자의 수는 최근 6년 동안 2012년도 6,075 명에서 2017년 6,561명으로 매년 $1.5 \%$ 의 소폭 증가세 를 보인다. 매출액을 살펴보면 2012년도 3,128억에서 2017 년도 5,483 억으로 연평균 $12 \%$ 의 높은 증가율은 보이는데 이것은 작동기능점검과 종합정밀점검대상이 확대된 영향 으로 분석된다.

\section{3 직무스트레스 개념}

직무스트레스는 모든 업무수행 과정 중에서 나타날 수 있는 현상으로, 일반적 스트레스 현상보다 명확하고 한정적 개념이다. 직무스트레스는 많은 학자들에 의해 다양하게 개인적 관점에서 정의 되어 왔다. Blau (1981)는 개인의 능력과 직무환경의 요구가 상충될 때 또는 개인의 목표와 직무환경이 부적합하여 충족시키지 못하는 경우 직무스트 레스가 발생한다고 보았다. Jang and Kwon (2006)는 개인과 외부환경 간의 상호측면에서 주목하여 개인이 주변 환경을 인지하고 평가하는 방법의 측면에서 이해하였다. 학자들에 따라, 연구목적에 따라 스트레스 요인은 차이를 보일 수 있으나 대체로 환경적요인, 개인역할요인, 조직특성 요인 등으로 구분하여 살펴 볼 수 있다.

이 연구는 직무스트레스를 '개인의 주관적 목표와 조직의 역할 및 요구에 대한 상호작용에 따른 불균형과 불일치로 야기되는 긴장 상태와 역할갈등'으로 정의한다.

\section{4 이직의도의 개념}

국립국어원(National Institute of the Korea Language) 표 준대사전에 의하면 이직은 직업을 바꾸거나 직장을 옮기는 것 또는 직업이나 직장을 그만두는 것을 말하고, 의도의 사전적 개념은 무엇을 하고 자 꾀하는 것을 말한다. 이직은 조직 행동론, 경제학, 심리학, 사회학 등 다양한 분야에서 연구되어온 노동이동(Labour Mobility)으로 이해되고 있다. 이직은 바라보는 다양한 관점이 있어 어느 측면에서 해석하 느냐에 따라 정의가 달라질 수 있다.

이직의 개념을 Kang (2015)은 범주에 따라서 협의적 이직 과 광의적 이직, 의사 결정 주체에 따라 자발적(Voluntary Turnover) 이직과 비자발적(Unvoluntary Turnover) 이직, 통제가능성에 따라 통제 가능이직과 통제 불가능 이직, 조직에 미치는 영향에 따라 순기능(Functional Turnover)과 역기능적 이직(Disfunctional Turnover)으로 구분하였다. 이 직 의도는 행동의 결과적 개념이 아니라 앞으로 나타날 행동 가능성으로 조직구성원이 자발적으로 조직을 떠나려 고 하는 의도 및 의지로써, 직장을 옮기고 싶다는 생각, 같은 직장 내에서 직종을 바꾸고 싶은 의지이며 현재의 상태에서 자신이 하는 일에서 벗어나고 싶은 정도이다. 이직 의도는 조직구성원이 조직을 이탈하려는 행동이나 태도를 말하며, Kim (2014)은 이직의도가 대표적인 조직유 효성 측정지표라고 밝히고 있다.
이 연구에서 이직의도를 척도로 사용한 이유는 자발적 이직의도를 파악하는데 이직률보다 유용한 척도라는 점에 서 때문이다.

\section{3. 연구 설계}

\section{1 자료분석방법}

이 연구는 2019년 5월 20일부터 8월 10 일에 걸쳐 소방시설 관리업 종사자를 대상으로 자기보고서 설문지법으로 실시 하였다. 설문을 위하여, 방문, 이메일과 우편접수도 병행하여 설문자료를 확보하였다. 설문지는 총 369 명이 참여하였으 나, 자료 활용에 적절치 못한 15 부를 빼고 유효한 354부에 한하여 연구 분석하였다. 이 연구의 분석을 위하여 SPSS $\mathrm{WIN} 25$ 프로그램를 이용하며 자료처리와 분석을 실시하였다.

첫째, 요인분석(Factor Analysis)2)을 실시하여 측정변수 가 선행이론과 동일하게 적재 되었는지를 확인하였다.

둘째, 신뢰성을 확인을 위해 요인분석에서 추출된 요인이 동질 변수들로 구성되어 있는지 신뢰도 분석(Reliability Analysis)을 실시하여 내적 일치도 계수(Cronbach's a)3)를 제시하였다.

셋째, 상관분석(Correlation Analysis)4)을 실시하여 변수 간의 관계강도를 판단하였다. 이 과정에서 변수간의 관련성 에 대한 대체적 윤곽이 제시된다.

넷째, 일원배치분산분석(One way ANOVA)5)을 실시하 여 인구사회학적 변수가 직무스트레스, 이직의도에 영향을 미치는지를 분석하였다.

다섯째, 직무스트레스와 이직의도간의 인과관계 분석을 위하여 회귀분석(Regression Analysis)6)을 실시하여 검증 하였다.

\section{2 측정도구}

이 연구에서는 Table 1에서 인구사회학적변수로 선정한 문항에 대하여 빈도분석하여 제시하였다.

변수로는 성별, 연령, 직급, 학력, 월 급여, 총 소방경력, 현 직장 경력, 자격사항, 담당업무가 있다.

소방시설관리업 종사자의 직무스트레스 측정을 위해 한

2) 요인분석에 있어 요인회전방식에는 사각회전방식과 직각회전방식이 있다. 직각회전방식에는 Quartmax, Varimax, Equamax방식이 있다. 여 기에서 사용한 배리맥스 요인회전방식은 하나의 요인에 높이 적재되 는 변수의 수를 줄여서 요인행렬의 열을 단순화시키는 방법이다.

3) 신뢰도 분석은 측정도구의 정확성이나 정밀성 즉 타당성을 나타내는데, Cronbach's $\alpha$ 값으로 제시하고 0.6 이상이면 신뢰도가 있다고 본다.

4) 상관분석은 변수간의 관련성을 나타내는 것으로 0 에서 \pm 1 사이로 나타 내며, \pm 1 에 가까울수록 상관관계가 높아지고 0 에 가까울수록 상관관 계는 낮아진다.

5) 일원배치분산분석은 두 집단 이상이 한 변수(종속변수)에 대한 평균 의 차이를 검정할 때 사용하며, 유의확률이 0.05 를 기준으로 채택여부 를 판단한다.

6) 다중회계분석은 독립변수 2 개 이상과 종속변수 1 개 간의 인과관계를 검정하는 것이다. 
Table 1. Demographic Characteristics Table

\begin{tabular}{|c|c|c|c|}
\hline \multicolumn{2}{|c|}{ Characteristics } & $\mathrm{N}$ & $\mathrm{N}(\%)$ \\
\hline \multirow{2}{*}{ Gender } & Female & 26 & 7.3 \\
\hline & Male & 328 & 92.7 \\
\hline \multirow{4}{*}{ Age (A) } & $\mathrm{A} \geq 50 \mathrm{~s}$ & 76 & 21.5 \\
\hline & $40 \mathrm{~s}$ & 86 & 24.3 \\
\hline & $30 \mathrm{~s}$ & 107 & 30.2 \\
\hline & $20 \mathrm{~s}$ & 85 & 24.0 \\
\hline \multirow{4}{*}{ Position } & over Deputy director & 133 & 37.6 \\
\hline & Section chief & 69 & 19.5 \\
\hline & Assistant manager & 86 & 24.3 \\
\hline & Staff & 66 & 18.6 \\
\hline \multirow{4}{*}{ Education } & Graduate school & 13 & 3.7 \\
\hline & University & 147 & 41.5 \\
\hline & College & 132 & 37.3 \\
\hline & $\leq$ High school & 62 & 17.5 \\
\hline \multirow{4}{*}{$\begin{array}{c}\text { Monthly } \\
\text { salary } \\
\text { (unit: } W \\
1,000,000)(\mathrm{P})\end{array}$} & $M \geq 3$ & 98 & 27.7 \\
\hline & $2.5 \leq \mathrm{M}<3.0$ & 65 & 18.4 \\
\hline & $2.0 \leq \mathrm{M}<2.5$ & 129 & 36.4 \\
\hline & $2.0<\mathrm{M}$ & 62 & 17.5 \\
\hline \multirow{4}{*}{$\begin{array}{c}\text { Total career } \\
\text { (TC) } \\
\text { Y: years }\end{array}$} & $\mathrm{TC} \geq 10 \mathrm{Y}$ & 122 & 34.5 \\
\hline & $5 \mathrm{Y} \leq \mathrm{TC}<10 \mathrm{Y}$ & 63 & 17.8 \\
\hline & $3 \mathrm{Y} \leq \mathrm{TC}<5 \mathrm{Y}$ & 75 & 21.2 \\
\hline & $3 \mathrm{Y}<\mathrm{TC}$ & 94 & 26.6 \\
\hline \multirow{4}{*}{$\begin{array}{l}\text { Present job } \\
\text { career (C) }\end{array}$} & $\mathrm{C} \geq 10 \mathrm{Y}$ & 53 & 15.0 \\
\hline & $5 \mathrm{Y} \leq \mathrm{C}<10 \mathrm{Y}$ & 77 & 21.8 \\
\hline & $3 \mathrm{Y} \leq \mathrm{C}<5 \mathrm{Y}$ & 74 & 20.9 \\
\hline & $3 \mathrm{Y}<\mathrm{C}$ & 150 & 42.4 \\
\hline \multirow{6}{*}{$\begin{array}{l}\text { Licence } \\
\text { of fire } \\
\text { fighting part }\end{array}$} & $\begin{array}{l}\text { Relevant qualification } \\
\text { certificate }\end{array}$ & 155 & 43.8 \\
\hline & Industrial engineer & 24 & 6.8 \\
\hline & Engineer & 114 & 32.2 \\
\hline & $\begin{array}{c}\text { Fire equipment } \\
\text { manager }\end{array}$ & 38 & 10.7 \\
\hline & $\begin{array}{c}\text { Fire equipment } \\
\text { manager } \& \\
\text { Professional engineer }\end{array}$ & 4 & 1.1 \\
\hline & et al. & 19 & 5.4 \\
\hline \multirow{7}{*}{ Task } & Inspection \& check & 190 & 53.7 \\
\hline & Safety management & 61 & 17.2 \\
\hline & Construction \& Repair & 43 & 12.1 \\
\hline & General affairs & 26 & 7.3 \\
\hline & Business sales & 2 & 0.6 \\
\hline & Business generalization & 22 & 6.2 \\
\hline & et al. & 10 & 2.8 \\
\hline
\end{tabular}

국산업안전공단 산업안전보건연구원의 “한국인 직무스트 레스 측정도구(Korean Scale of Occupational Stress)의 정확 성 및 신뢰성 평가연구”의 직무스트레스 측정도구를 활용 하였다.

이 도구는 ‘물리적 환경(SS-1)', ‘직무요구(SS-2)', ‘직무 자율(SS-3)', '관계갈등(SS-4)', '직무불안정(SS-5)', ‘조직 체계(SS-6)', '기대보상(SS-7)', '직장문화(SS-8)'로 8개영 역으로 구분되어 있는데 이를 수정, 보완 사용하였다. 직무 스트레스의 세분화된 하위 항목으로 물리 환경 3 문항, 직무 요구 8 문항, 직무자율 5 문항, 관계갈등 4 문항, 직무불안정 6 문항, 조직체계 7 문항, 보상부적절 6 문항, 직장문화 4 문항 을 설문지로 활용하였다. 여기에 직무요구 4 문항을 추가하 여 12 문항으로 구성하였다. 결과적으로 총 47 문항으로 구성 하였다. 이직의도 문항은 Cho (2013)의 설문지를 재인용하 여 작성되었고, 총 9 문항으로 구성하였다. 각 설문 척도는 4점 Likert 척도7)로 구성하였다.

\section{3 자료 분석}

\subsection{1 직무스트레스의 요인분석 및 신뢰도 분석}

직무스트레스에 대한 요인 분석결과 결과는 하위척도 8 가지 중 ‘직장문화'의 척도는 척도순화과정을 통하여 배제 하였다.

이 연구의 측정변수에 대하여, 주성분분석8), 베리맥스 요인회전, $\mathrm{KMO}$ 와 Bartlette의 구형성 검증9)을 실시하였다. 요인분석 과정에서 직무스트레스 요인 중 '직무요구' 하위 척도 6번(ㅍ-06) 항목, ‘직무불안정' 하위척도 중 1번, 2번, 4번( $\amalg 5-01,02,04)$, ‘보상부적절’ 하위척도 중 3번( $\Pi 7-03)$, 마지막으로 '직장문화’ 하위척도(II8-01, 02, 03, 04)이 선행 연구와 다르게 적재되어 총 9문항의 변수를 제거하였다. Table 2에 직무스트레스에 대한 요인분석 결과와 하위척도 에 대한 신뢰도를 제시하였다. 신뢰도 분석 결과, 내적 일치 도 계수 $\mathrm{a}$ 값이 전체 척도에서 0.908 로 신뢰도가 있다고 판단하였다.

7) 리커트는 문항에 대한 응답자의 긍정과 부정의 정도에 따른 척도를 등간격으로 나누어 구성한다. 일반적인 리커트 척도는 문항들에 대한 찬성과 반대의 정도를 두 극단으로 나누고, 그 사이의 간격을 보통 2 7 단계로 나눈다. 각 단계별 간격은 일정한 것으로 간주한다. 척도 의 응답 개수가 늘어나면 척도의 신뢰도가 증가하게 된다. 통계적 신뢰도를 높이기 위해 보통 5점 척도를 많이 사용하며, "매우 그렇지 않다, 그렇지 않다, 보통이다, 그렇다, 매우 그렇다" 등으로 구성된다. 4점 척도의 경우는 중립적인 응답 범주를 뺀 "매우 그렇지 않다, 그렇 지 않다, 보통이다, 그렇다, 매우 그렇다"로 구성된다.

8) 주성분분석은 변수들을 요인들의 선형결합으로 가정하는 것으로 표 본의 분산을 가장 잘 설명해주고 주성분과 무관한 분산을 가장 많이 설명해주는 선형결합이다. 공통성이 0.4 이하이면 낮다고 판정한다.

9) $\mathrm{KMO}$ 와 Bartlette의 구형성 검증은 변수들간의 상관관계가 다른변수에 의해 잘설명되는 정도를 나타내는 값이다. $\mathrm{KMO}$ 값이 적으면 요인분 석을 위한 변수의 선정이 좋지 못함을 나타낸다. 
Table 2. Composition of Question by Subscale to Job Stress, Factor Analysis and Reliability

\begin{tabular}{|c|c|c|c|c|c|c|c|}
\hline \multicolumn{2}{|c|}{ Subscale } & \multirow{2}{*}{$\begin{array}{c}\text { No. } \\
\text { Items }\end{array}$} & \multicolumn{2}{|r|}{$\begin{array}{c}\text { Question } \\
\text { No. }\end{array}$} & \multirow{2}{*}{$\begin{array}{c}\text { Eigen value } \\
(>1)^{10)}\end{array}$} & \multirow{2}{*}{$\begin{array}{c}\begin{array}{c}\text { Explanatory } \\
\text { power }^{11)}\end{array} \\
6.172\end{array}$} & \multirow{2}{*}{$\begin{array}{c}\text { Reliability } \\
(a)\end{array}$} \\
\hline \multirow{7}{*}{$\begin{array}{c}\text { Job } \\
\text { Stress }\end{array}$} & SS-1 & & II 1 & $1 *, 2,3$ & & & \\
\hline & SS-2 & 11 & П 2 & $1,2,3,4,5,7,8,9,10,11,12$ & 5.412 & 15.462 & 0.883 \\
\hline & SS-3 & 2 & II 3 & $4^{*}, 5^{*}$ & 1.706 & 4.875 & 0.609 \\
\hline & SS-4 & 4 & II 4 & $1^{*}, 2^{*}, 3^{*}, 4^{*}$ & 2.498 & 7.137 & 0.762 \\
\hline & SS-5 & 3 & II 5 & $3,5,6$, & 2.094 & 5.982 & 0.753 \\
\hline & SS-6 & 7 & $\Pi 6$ & $1^{*}, 2^{*}, 3^{*}, 4^{*}, 5^{*}, 6^{*}, 7^{*}$ & 4.152 & 11.864 & 0.868 \\
\hline & SS-7 & 5 & II 7 & $1,2^{*}, 4^{*}, 5^{*}, 6^{*}$ & 2.742 & 7.836 & 0.799 \\
\hline \multicolumn{2}{|c|}{ Total } & 35 & & * reverse items & & & 0.908 \\
\hline
\end{tabular}

Table 3. Factor Analysis and Reliability

\begin{tabular}{c|c|c|c}
\hline Subscale & No. Items & Question No. & Reliability (a) \\
\hline Turnover Intention & 9 & III1-01,02,03,04,05*,06,07,08,09 & 0.907 \\
\hline Total & 9 & $*$ reverse item & \\
\hline
\end{tabular}

Table 4. Inter-Construct Correlations

\begin{tabular}{|c|c|c|c|c|c|c|c|c|c|c|c|}
\hline \multirow{2}{*}{\multicolumn{2}{|c|}{ Variables/Subscale }} & \multirow{3}{*}{$\begin{array}{l}\mathrm{M}^{12)} \\
2.430\end{array}$} & \multirow{3}{*}{$\begin{array}{l}\mathrm{SD}^{13)} \\
0.643\end{array}$} & \multicolumn{8}{|c|}{ Inter-Construct Correlations } \\
\hline & & & & \multirow{2}{*}{$\begin{array}{c}(1) \\
1\end{array}$} & \multirow[t]{2}{*}{ (2) } & \multirow[t]{2}{*}{ (3) } & \multirow[t]{2}{*}{ (4) } & \multirow[t]{2}{*}{ (5) } & \multirow[t]{2}{*}{ (6) } & \multirow[t]{2}{*}{ (7) } & \multirow[t]{2}{*}{ (8) } \\
\hline \multirow{7}{*}{ Job Stress } & 1 & & & & & & & & & & \\
\hline & 2 & 2.578 & 0.523 & $.457 * *$ & 1 & & & & & & \\
\hline & 3 & 2.461 & 0.604 & .055 & -.048 & 1 & & & & & \\
\hline & 4 & 2.053 & 0.470 & $.105 *$ & $.176^{* *}$ & $.110^{*}$ & 1 & & & & \\
\hline & 5 & 2.066 & 0.569 & $.208 * *$ & $.242 * *$ & .069 & $.345^{* *}$ & 1 & & & \\
\hline & 6 & 2.305 & 0.482 & $.340 * *$ & $.373 * *$ & $.148^{* *}$ & $.447 * *$ & $.404 * *$ & 1 & & \\
\hline & 7 & 2.415 & 0.530 & $.246^{* *}$ & $.384 * *$ & $.187^{* *}$ & $.412 * *$ & $.404 * *$ & $.623 * *$ & 1 & \\
\hline \multicolumn{2}{|c|}{ 8.Turnover Intention } & 2.396 & 0.567 & $.273 * *$ & $.332 * *$ & $.115^{*}$ & $.245^{* *}$ & $.296^{* *}$ & $.568 * *$ & $.588^{* *}$ & 1 \\
\hline
\end{tabular}

Subscale No.

(1) Physical environment, (2) Excessive Job Demands, (3) Insufficient Job Control,

(4) Interpersonal Relation Conflict, (5) Job Insecurity, (6) Organizational System,

(7) Lake of Reward, (8) Turnover Intention

\subsection{2 이직의도의 신뢰도 분석}

Table 3에 이직의도 척도에 대한 신뢰도 분석결과인 크론 바흐 a 값을 0.907 로 분석 제시하였다.

\subsection{3 상관관계분석}

측정 변수들 간의 상관관계는 Table 4에 제시하였다. 구체적으로 이직의도는 직무스트레스의 하위변수 중 조직 체계와 보상부적절의 상관계수가 각각 0.568 과 0.588 로 다 소 높은 상관관계를 보였다.

10) 고유값은 특정요인에 적재된 모든 변수의 적재량을 제곱하여 합한 값을 말하는 것으로 특정요인에 관련된 표준화된 분산을 가리킨다. 사회관학 분야에서 요인과 문항의 선택기준은 고유값(Engin Value)은 1.0 이상으로 기준한다.

11) 분산의 설명력은 요인이 전체에서 어느 정도 설명하는지를 나타내는 수치이다.

12) 평균값(mean)을 의미한다.

13) 표준편차(Std. Deviation)을 나타낸다.

\section{4. 연구 결과 및 분석}

\section{1 연구문제}

이 연구는 소방시설관리업종사에 대하여 다음과 같은 가설을 설정하였다.

가설 1. 사회과학적 변수에 의한 직무스트레스는 유의미 한 차이가 있을 것이다.

가설 2. 직무스트레스가 이직의도에 정 $(+)$ 의 영향을 미칠 것이다.

가설 2.1. “물리환경”의 스트레스가 높을수록 이직의도에 정 $(+)$ 의 영향을 미칠 것이다.

가설 2.2. “직무요구”의 스트레스가 높을수록 이직의도에 정 $(+)$ 의 영향을 미칠 것이다.

가설 2.3. “직무자율"의 스트레스가 높을수록 이직의도에 정 $(+)$ 의 영향을 미칠 것이다. 
가설 2.4. “관계갈등”의 스트레스가 높을수록 이직의도에 정 $(+)$ 의 영향을 미칠 것이다.

가설 2.5. “직무불안정”의 스트레스가 높을수록 이직의도 에 정(+)의 영향을 미칠 것이다.

가설 2.6. "조직체계"의 스트레스가 높을수록 이직의도에 정 $(+)$ 의 영향을 미칠 것이다.

가설 2.7. “보상부적절”의 스트레스가 높을수록 이직의도 에 정(+)의 영향을 미칠 것이다.

\section{2 가설 검정}

\subsection{1 사회과학적 변수에 따른 직무스트레스의 차이}

대상자들의 사회과학적 변수에 따른 일원배치분산분석 분석결과는 Table 5 와 같다.

사회과학적 변수에 대한 직무스트레스의 집단 간의 차이 를 분석하면 직급 간, 전 경력 간, 자격증 간, 담당 업무
간에서 유의한 차이가 있었다. 연령에 따른 집단 간 직무스트 레스 F값은 2.321, 유의확률 P값은 0.075 로 통계적으로 유의 한 차이를 나타내지 않으나, 하위요인인 '직무요구'에서는 $\mathrm{F}$ 값은 3.821, P값은 0.010 으로 20대가 40대에 비하여 스트레 스가 높은 유의한 차이가 있으며, '직무자율'척도의 $\mathrm{F}$ 값은 $5.243, \mathrm{P}$ 값은 0.001 로 20 대가 40 대에 비하여 반대로 높게 났으며, ‘관계갈등' F값은 $11.850, \mathrm{P}$ 값은 0.000 로 50 대, 40 대, 20 대, 30 대순으로 높게 유의한 차이를 보였다. 세부내용은 Table 6에 수록하였다. 연령에 따라 집단 간의 유의미한 차이가 없어 Cho (2013)의 연구를 지지한 결과가 나왔다.직 급에 따른 일원배치분석 결과 $\mathrm{F}$ 값은 2.823 이고 $\mathrm{P}$ 값은 0.039 $\left(\mathrm{p}^{*}<.05\right)$ 으로 나타나 유의한 결과를 나타냈다. 구체적으로 하부척도를 분석하면 ‘직무요구' 척도에서는 과장이상의 직급그룹이 타 하위직급 그룹보다 가장 스트레스가 크게 나타났다. '직무자율'에서는 사원과 대리 그룹이 과장이상 그룹보다 스트레스가 크게 나타나 조직 내 활동에서 자율적

Table 5. The Group Difference of Comparison of Job Stress by General Characteristics

\begin{tabular}{|c|c|c|c|c|c|c|c|}
\hline Charateristics & Category & $\mathrm{N}$ & Mean & SD & $\mathrm{F}^{14)}$ & $\mathrm{P}^{15)}$ & Scheffe $^{16)}$ \\
\hline \multirow{4}{*}{ Age } & 20s (a) & 85 & 2.316 & 0.379 & \multirow{4}{*}{2.321} & \multirow{4}{*}{0.075} & \multirow{4}{*}{ N/A } \\
\hline & $30 \mathrm{~s}(\mathrm{~b})$ & 107 & 2.357 & 0.372 & & & \\
\hline & $40 \mathrm{~s}(\mathrm{c})$ & 86 & 2.452 & 0.297 & & & \\
\hline & $A \geq 50 \mathrm{~s}(\mathrm{~d})$ & 76 & 2.388 & 0.338 & & & \\
\hline \multirow{4}{*}{ Position } & Staff (a) & 66 & 2.308 & 0.349 & \multirow{4}{*}{2.823} & \multirow{4}{*}{$0.039^{*}$} & \multirow{4}{*}{$\mathrm{a}<\mathrm{c}$} \\
\hline & Assistant manager (b) & 86 & 2.321 & 0.313 & & & \\
\hline & Section chief (c) & 69 & 2.430 & 0.381 & & & \\
\hline & over Deputy director (d) & 133 & 2.420 & 0.354 & & & \\
\hline \multirow{3}{*}{ Education level } & $\leq$ High school & 62 & 2.330 & 0.363 & \multirow{3}{*}{0.693} & \multirow{3}{*}{0.501} & \multirow{3}{*}{ N/A } \\
\hline & College & 132 & 2.384 & 0.376 & & & \\
\hline & University \& Graduate school & 160 & 2.390 & 0.330 & & & \\
\hline \multirow{4}{*}{$\begin{array}{l}\text { Monthly salary } \\
\text { (unit: } W 1,000)(P)\end{array}$} & $2,000<\mathrm{M}(\mathrm{a})$ & 62 & 2.312 & 0.345 & \multirow{4}{*}{2.159} & \multirow{4}{*}{0.093} & \multirow{4}{*}{ N/A } \\
\hline & $2,000 \leq M<2,500$ (b) & 129 & 2.348 & 0.371 & & & \\
\hline & $2,500 \leq \mathrm{M}<3,000$ (c) & 65 & 2.401 & 0.317 & & & \\
\hline & $\mathrm{M} \geq 3,000(\mathrm{~d})$ & 98 & 2.440 & 0.345 & & & \\
\hline \multirow{4}{*}{ Total career } & $3<$ TC years $(a)$ & 94 & 2.298 & 0.326 & \multirow{4}{*}{2.662} & \multirow{4}{*}{$0.048^{*}$} & \multirow{4}{*}{$\mathrm{a}<\mathrm{d}$} \\
\hline & $3 \leq \mathrm{TC}<5$ years $(\mathrm{b})$ & 75 & 2.376 & 0.379 & & & \\
\hline & $5 \leq \mathrm{TC}<10$ years $(\mathrm{c})$ & 63 & 2.388 & 0.319 & & & \\
\hline & $\mathrm{TC} \geq 10$ years $(\mathrm{d})$ & 122 & 2.433 & 0.362 & & & \\
\hline \multirow{3}{*}{ Licence } & Relevant qualification certificate, etc. (a) & 174 & 2.337 & 0.339 & \multirow{3}{*}{3.312} & \multirow{3}{*}{$0.038^{*}$} & \multirow{3}{*}{$\mathrm{a}<\mathrm{c}$} \\
\hline & Industrial engineer, Engineer (b) & 138 & 2.394 & 0.376 & & & \\
\hline & $\begin{array}{c}\text { Fire equipment manager, } \\
\text { Professional engineer }\end{array}$ & 42 & 2.485 & 0.295 & & & \\
\hline \multirow{3}{*}{ Task } & Inspection \& check (a) & 190 & 2.438 & 0.353 & \multirow{3}{*}{7.065} & \multirow{3}{*}{$0.001 * *$} & \multirow{3}{*}{$\mathrm{a}>\mathrm{c}$} \\
\hline & Safety management (b) & 61 & 2.349 & 0.352 & & & \\
\hline & Construction, Repair \& etc. (c) & 103 & 2.281 & 0.322 & & & \\
\hline
\end{tabular}

14) $\mathrm{F}$ 값은 집단 간 변량/집단 내 변량의 비로써 두 개 이상의 복수의 집단을 대상으로 하여 각 집단의 평균을 서로 비교하는 분산분석의 검정 통계값을 의미한다. 집단의 차이가 있다면 $\mathrm{F} \gg 1$ 이 된다.
$15)$ 사회과학에서 유의도 수준 $\alpha=0.05$ 또는 $\mathrm{P}<.05$ 를 기준으로 한다. 16) 독립변수의 각 집단별 평균의 차이를 검정하는 사후검정결과 방법임. 
Table 6. The Group Difference of Comparison of Job Stress by Age

\begin{tabular}{|c|c|c|c|c|c|c|c|c|c|c|c|}
\hline \multirow{3}{*}{\multicolumn{2}{|c|}{ Variable }} & \multicolumn{8}{|c|}{ Age } & \multirow{3}{*}{$\mathrm{F}$} & \multirow{3}{*}{$\begin{array}{c}P \\
\text { (Scheffe) }\end{array}$} \\
\hline & & \multicolumn{2}{|c|}{ (1) } & \multicolumn{2}{|c|}{ (2) } & \multicolumn{2}{|c|}{ (3) } & \multicolumn{2}{|c|}{ (4) } & & \\
\hline & & $\mathrm{M}$ & $\mathrm{SD}$ & $\mathrm{M}$ & $\mathrm{SD}$ & $\mathrm{M}$ & $\mathrm{SD}$ & $\mathrm{M}$ & SD & & \\
\hline \multirow{8}{*}{$\begin{array}{c}\text { Job } \\
\text { Stress }\end{array}$} & SS-1 & 2.44 & .689 & 2.41 & .693 & 2.52 & .552 & 2.34 & .611 & 1.129 & 0.337 \\
\hline & SS-2 & $2.46^{\mathrm{a}}$ & .564 & $2.60^{\mathrm{b}}$ & .544 & $2.71^{\mathrm{c}}$ & .441 & $2.52^{\mathrm{d}}$ & .499 & 3.821 & $0.010^{*}(\mathrm{a}<\mathrm{c})$ \\
\hline & SS-3 & $2.64^{\mathrm{a}}$ & .688 & $2.50^{\mathrm{b}}$ & .675 & $2.30^{\mathrm{c}}$ & .493 & $2.40^{\mathrm{d}}$ & .442 & 5.243 & $0.001 * *(\mathrm{a}>\mathrm{c})$ \\
\hline & SS-4 & $1.96^{\mathrm{a}}$ & .456 & $1.91^{\mathrm{b}}$ & .497 & $2.15^{\mathrm{c}}$ & .359 & $2.26^{\mathrm{d}}$ & .465 & 11.850 & $\begin{array}{c}0.000^{* * *} \\
(\mathrm{~b}<\mathrm{c}, \mathrm{a}, \mathrm{b}<\mathrm{d})\end{array}$ \\
\hline & SS-5 & 2.01 & .610 & 2.00 & .631 & 2.12 & .468 & 2.16 & .526 & 1.694 & 0.168 \\
\hline & SS-6 & 2.30 & .558 & 2.30 & .520 & 2.36 & .386 & 2.34 & .430 & 1.082 & 0.357 \\
\hline & SS-7 & 2.38 & .585 & 2.39 & .533 & 2.47 & .509 & 2.42 & .488 & 0.564 & 0.639 \\
\hline & Total & 2.32 & .379 & 2.36 & .372 & 2.45 & .297 & 2.39 & .338 & 2.321 & 0.075 \\
\hline
\end{tabular}

NOTE. Age (1) 20s (a), (2) 30s (b), (3) 40s (c), (4) $\mathrm{A} \geq 50 \mathrm{~s}$ (d), $\mathrm{p}^{*}<.05, \mathrm{p}^{* *}<.01, \mathrm{p}^{* * *}<.001$

Table 7. The Group Difference of Comparison of Job Stress by Position

\begin{tabular}{|c|c|c|c|c|c|c|c|c|c|c|c|}
\hline \multirow{2}{*}{\multicolumn{2}{|c|}{ Variable }} & \multicolumn{8}{|c|}{ Position } & \multirow{3}{*}{$\mathrm{F}$} & \multirow{3}{*}{$\begin{array}{c}\mathrm{P} \\
\text { (Scheffe) }\end{array}$} \\
\hline & & \multicolumn{2}{|c|}{ (1) } & \multicolumn{2}{|c|}{ (2) } & \multicolumn{2}{|c|}{ (3) } & \multicolumn{2}{|c|}{ (4) } & & \\
\hline & & $\mathrm{M}$ & $\mathrm{SD}$ & M & SD & $M$ & $\mathrm{SD}$ & M & $\mathrm{SD}$ & & \\
\hline \multirow{8}{*}{$\begin{array}{c}\text { Job } \\
\text { Stress }\end{array}$} & SS-1 & 2.38 & .654 & 2.42 & .677 & 2.40 & .596 & 2.48 & .644 & .396 & 0.765 \\
\hline & SS-2 & $2.40^{\mathrm{a}}$ & .572 & $2.54^{\mathrm{b}}$ & .487 & $2.67^{\mathrm{c}}$ & .509 & $2.64^{\mathrm{d}}$ & .522 & 3.984 & $0.008^{* *}(\mathrm{a}<\mathrm{c}, \mathrm{d})$ \\
\hline & SS-3 & $2.92^{\mathrm{a}}$ & .692 & $2.45^{\mathrm{b}}$ & .584 & $2.36^{\mathrm{c}}$ & .508 & $2.29^{\mathrm{d}}$ & .497 & 19.784 & $0.000^{* * *}(\mathrm{a}>\mathrm{b}, \mathrm{c}, \mathrm{d})$ \\
\hline & SS-4 & $1.98^{\mathrm{a}}$ & .455 & $1.91^{\mathrm{b}}$ & .459 & $2.02^{\mathrm{c}}$ & .454 & $2.20^{\mathrm{d}}$ & .455 & 8.493 & $0.000 * * *(\mathrm{a}, \mathrm{b}<\mathrm{c}, \mathrm{d})$ \\
\hline & SS-5 & $2.04^{\mathrm{a}}$ & .594 & $1.92^{\mathrm{b}}$ & .562 & $2.14^{\mathrm{c}}$ & .598 & $2.14^{\mathrm{d}}$ & .532 & 3.140 & $0.025^{*}(\mathrm{a}<\mathrm{c}, \mathrm{d})$ \\
\hline & SS-6 & 2.23 & .523 & 2.26 & .452 & 2.38 & .538 & 2.33 & .445 & 1.525 & 0.208 \\
\hline & SS-7 & 2.35 & .542 & 2.38 & .526 & 2.52 & .554 & 2.42 & .512 & 1.468 & 0.223 \\
\hline & Total & 2.31 & .349 & 2.32 & .313 & 2.43 & .381 & 2.42 & .354 & 2.823 & $0.039 *$ \\
\hline
\end{tabular}

NOTE. Position (1) Staff (a), (2) Assistant manager (b), (3) Section chief (c), (4) Over Deputy director (d)

Table 8. The Group Difference of Comparison of Job Stress by Monthly Salary

\begin{tabular}{|c|c|c|c|c|c|c|c|c|c|c|c|}
\hline \multirow{3}{*}{\multicolumn{2}{|c|}{ Variable }} & \multicolumn{8}{|c|}{ Payment } & \multirow{3}{*}{$\mathrm{F}$} & \multirow{3}{*}{$\begin{array}{c}\mathrm{P} \\
\text { (Scheffe) }\end{array}$} \\
\hline & & \multicolumn{2}{|c|}{ (1) } & \multicolumn{2}{|c|}{ (2) } & \multicolumn{2}{|c|}{ (3) } & \multicolumn{2}{|c|}{ (4) } & & \\
\hline & & M & $\mathrm{SD}$ & M & $\mathrm{SD}$ & M & SD & $\mathrm{M}$ & SD & & \\
\hline \multirow{8}{*}{$\begin{array}{c}\text { Job } \\
\text { Stress }\end{array}$} & SS-1 & 2.33 & .624 & 2.42 & .715 & 2.47 & .546 & 2.48 & .617 & 0.764 & 0.515 \\
\hline & SS-2 & $2.40^{\mathrm{a}}$ & .553 & $2.55^{\mathrm{b}}$ & .544 & $2.61^{\mathrm{c}}$ & .426 & $2.71^{\mathrm{d}}$ & .499 & 5.185 & $0.002 * *(a<d)$ \\
\hline & SS-3 & $2.81^{\mathrm{a}}$ & .622 & $2.50^{\mathrm{b}}$ & .627 & $2.32^{\mathrm{c}}$ & .504 & $2.29^{\mathrm{d}}$ & .523 & 12.299 & $0.000 * * *(a>d)$ \\
\hline & SS-4 & $2.02^{\mathrm{a}}$ & .411 & $1.93^{\mathrm{b}}$ & .443 & $2.12^{\mathrm{c}}$ & .504 & $2.20^{\mathrm{d}}$ & .474 & 7.042 & $0.000 * * *(b<d)$ \\
\hline & SS-5 & 1.95 & .554 & 2.10 & .600 & 2.10 & .564 & 2.08 & .540 & 1.122 & 0.340 \\
\hline & SS-6 & 2.24 & .458 & 2.27 & .531 & 2.33 & .446 & 2.37 & .450 & 1.138 & 0.334 \\
\hline & SS-7 & 2.47 & .572 & 2.40 & .537 & 2.44 & .504 & 2.38 & .516 & 0.392 & 0.759 \\
\hline & Total & 2.31 & .345 & 2.35 & .371 & 2.40 & .317 & 2.44 & .344 & 2.159 & 0.093 \\
\hline
\end{tabular}

NOTE. Monthly salary (unit: $W 1,000,000$ ) (1) $2.0<\mathrm{M}$ (a), (2) $2.0 \leq \mathrm{M}<2.5$ (b), (3) $2.5 \leq \mathrm{M}<3.0$ (c), (4) $\mathrm{M} \geq 3.0$ (d) $\mathrm{p}^{*}<.05, \mathrm{p}^{* *}<.01, \mathrm{p}^{* * *}<.001$

직무수행에 한계가 있는 것으로 분석된다.

이는 직위에 따른 조직의 활동에 적극적으로 참여가 요구 되어지며, 직급이 올라 갈수록 많은 역할이 부여되어 스트레 스가 더 많이 받는다고 분석한 Yang (2010)의 연구를 지지한 다고 할 수 있다. 반대로 Cho (2013)의 연구에서는 직급이 낮을수록 스트레스를 더 받는다는 보고도 있다. 세부 하위척
도에 대한 내용은 Table 7에 제시하였다.

급여에 따른 집단 간의 차이 분석결과 $\mathrm{F}$ 값은 2.159 이고 $\mathrm{P}$ 값은 $0.093\left(\mathrm{p}^{*}>.05\right)$ 으로 나타나 전체적으로는 유의한 결과를 나타 내지 않았으며 내용은 Table 8과 같다. 이는 선행연구에서 $\mathrm{Kim}$ (2018)과 $\mathrm{Bae}$ (2019)의 연구를 지지하는 결과이다. 다른 연구에서는 유의수준 하에서 Ko (2008)와 
Cho (2013)는 급여가 작을수록 스트레스가 크다는 연구와 Lee (2004)와 Lee (2007)는 급여가 높을수록 스트레스가 크다는 연구가 상존한다.

대체로 이 연구에서는 급여가 높을수록 스트레스가 큰 경향성을 보인다. 구체적으로 하부척도를분석하면 ‘직무요 구'에서는 Scheffe분석결과 급여가 300 만원 이상 그룹이 200 만원 미만 그룹보다 유의하게 높게 나타났다. 유의확률 $\mathrm{P}$ 는 0.002 이다. '직무자율'에서는 반대로 200 만원 미만 그룹 이 300 만원 이상 그룹보다 유의하게 높게 나타났다. 유의확 률 $\mathrm{P}$ 는 0.000 이다. 직급과 급여에 있어서 집단 간의 직무스트 레스 차이가 유사한 경향을 보이는 것은 변수간의 상호 밀접한 상관관계가 있음을 보여주고 있다.

전체 경력에 따른 일원배치분산결과 $\mathrm{F}$ 값은 2.622 이고 $\mathrm{P}$ 값은 $0.048\left(\mathrm{p}^{*}<05\right)$ 로 나타나 유의한 집단 간의 차이를 확인하였고, 내용은 Table 9와 같다. 특이한 점은 하부척도 중 '조직체계'에 대하여 차이가 발생되었다.

자격증에 따른 집단 간의 차이를 알아보기 위하모집단이 최초 6 개의 분류로 되어 있으나, 자격증 취득과정과 등급을
고려하여 3 개의 집단으로 재분류하였다. 우선, 소방인정자 격수첩소지자와 단순보조자를 그룹1로, 소방산업기사와 소방기사를 그룹2로, 소방관리사 보유 그룹을 그룹3으로 하여 분석하였다. 분석 결과 $\mathrm{F}$ 값은 3.312 이고 $\mathrm{P}$ 값은 0.038 (p*<05)로 나타나 전체적으로는 유의한 결과를 나타냈으며 내용은 Table 10 에 제시하였다.

Scheffe사후분석 결과 '직무요구'에 대한 하위척도에서 소방시설관리사 보유 그룹( $\mathrm{M}=2.89)$ 이 그룹 $1(\mathrm{M}=2.50)$ 보다 과도한 스트레스를 받는 것으로 나타났으며, 이는 직무분야 (Task)의 소방점검 그룹의 평균(M=2.63)보다도 훨씬 큰 것을 확인할 수 있다. 이와 같은 이유는 소방시설관리업의 주 인력에 따른 과도한 책임과 업무의 과중 등에 기인한다고 볼 수 있다. Lim and Kong (2019a)은 소방시설관리사의 업무 가 점검참여에서부터 점검결과 보고서 발행까지의 일련의 업무진행 즉, 기술적 - 법적 문제점 검토, 연혁법령 및 연혁 법령 확인, 시공 방법 검토 관계인 결과서 초안 작성 - 송부 및 관계인 협의 등 모든 과정을 책임지고 있다고 밝히고 있다. 소방시설관리협회의 자료에 따르면, 2015년부터 2018

Table 9. The Group Difference of Comparison of Job Stress by Total Career

\begin{tabular}{|c|c|c|c|c|c|c|c|c|c|c|c|}
\hline \multirow{3}{*}{\multicolumn{2}{|c|}{ Variable }} & \multicolumn{8}{|c|}{ Total career } & \multirow{3}{*}{$\mathrm{F}$} & \multirow{3}{*}{$\begin{array}{c}\mathrm{P} \\
(\text { Scheffe })\end{array}$} \\
\hline & & \multicolumn{2}{|c|}{ (1) } & \multicolumn{2}{|c|}{ (2) } & \multicolumn{2}{|c|}{ (3) } & \multicolumn{2}{|c|}{ (4) } & & \\
\hline & & $\mathrm{M}$ & SD & $\mathrm{M}$ & SD & $\mathrm{M}$ & $\mathrm{SD}$ & $M$ & $\mathrm{SD}$ & & \\
\hline \multirow{8}{*}{$\begin{array}{c}\text { Job } \\
\text { Stress }\end{array}$} & SS-1 & 2.39 & .671 & 2.44 & .756 & 2.43 & .572 & 2.46 & .585 & 0.230 & 0.875 \\
\hline & SS-2 & 2.46 & .532 & 2.58 & .526 & 2.63 & .509 & 2.64 & .511 & 2.380 & 0.069 \\
\hline & SS-3 & $2.71^{\mathrm{a}}$ & .653 & $2.49^{\mathrm{b}}$ & .604 & $2.34^{\mathrm{c}}$ & .538 & $2.32^{\mathrm{d}}$ & .539 & 9.007 & $0.000^{* * *}(\mathrm{a}>\mathrm{c}, \mathrm{d})$ \\
\hline & SS-4 & $1.95^{\mathrm{a}}$ & .394 & $2.01^{\mathrm{b}}$ & .507 & $2.05^{\mathrm{c}}$ & .399 & $2.16^{\mathrm{d}}$ & .514 & 4.017 & $0.008^{* *}(\mathrm{a}<\mathrm{d})$ \\
\hline & SS-5 & 2.06 & .554 & 2.01 & .637 & 2.04 & .557 & 2.12 & .546 & 0.663 & 0.575 \\
\hline & SS-6 & $2.14^{\mathrm{a}}$ & .456 & $2.35^{\mathrm{b}}$ & .524 & $2.34^{\mathrm{c}}$ & .423 & $2.39^{\mathrm{d}}$ & .479 & 5.337 & $0.001^{* *}(\mathrm{a}<\mathrm{d})$ \\
\hline & SS-7 & 2.36 & .561 & 2.05 & .540 & 2.39 & .463 & 2.47 & .533 & 0.843 & 0.471 \\
\hline & Total & 2.30 & .326 & 2.38 & .379 & 2.39 & .319 & 2.43 & .362 & 2.662 & $0.048^{*}(\mathrm{a}<\mathrm{d})$ \\
\hline
\end{tabular}

NOTE. Total career (1) $3 \mathrm{Y}<\mathrm{TC}$ (a), (2) $3 \mathrm{Y} \leq \mathrm{TC}<5 \mathrm{Y}(\mathrm{b})$, (3) $5 \mathrm{Y} \leq \mathrm{TC}<10 \mathrm{Y}$, (4) TC $\geq 10 \mathrm{Y}$,

$\mathrm{p}^{*}<.05, \mathrm{p}^{* *}<.01, \mathrm{p}^{* * *}<.001$

Table 10. The Group Difference of Comparison of Job Stress by Licence

\begin{tabular}{|c|c|c|c|c|c|c|c|c|c|}
\hline & & \multicolumn{6}{|c|}{ Total career } & \multirow{3}{*}{$\mathrm{F}$} & \multirow{3}{*}{$\begin{array}{c}\mathrm{P} \\
\text { (Scheffe) }\end{array}$} \\
\hline \multirow{2}{*}{\multicolumn{2}{|c|}{ Variable }} & \multicolumn{2}{|c|}{ (1) } & \multicolumn{2}{|c|}{ (2) } & \multicolumn{2}{|c|}{ (3) } & & \\
\hline & & $\mathrm{M}$ & $\mathrm{SD}$ & $\mathrm{M}$ & $\mathrm{SD}$ & $\mathrm{M}$ & $\mathrm{SD}$ & & \\
\hline \multirow{8}{*}{$\begin{array}{c}\text { Job } \\
\text { Stress }\end{array}$} & SS-1 & 2.38 & .629 & 2.45 & .663 & 2.58 & .621 & 1.863 & 0.157 \\
\hline & SS-2 & $2.50^{\mathrm{a}}$ & .508 & $2.58^{\mathrm{b}}$ & .532 & $2.89^{\mathrm{c}}$ & .434 & 9.979 & $0.000^{* * *}(\mathrm{a}, \mathrm{b}<\mathrm{c})$ \\
\hline & SS-3 & $2.55^{\mathrm{a}}$ & .614 & $2.43^{\mathrm{b}}$ & .584 & $2.21^{\mathrm{c}}$ & .565 & 5.571 & $0.004 * *(a, b<c)$ \\
\hline & SS-4 & $1.99^{\mathrm{a}}$ & .452 & $2.10^{\mathrm{b}}$ & .509 & $2.15^{\mathrm{c}}$ & .375 & 3.271 & $0.039 *(a, b<c)$ \\
\hline & SS-5 & 2.03 & .535 & 2.06 & .612 & 2.21 & .556 & 1.549 & 0.214 \\
\hline & SS-6 & 2.29 & .474 & 2.33 & .515 & 2.27 & .405 & 0.361 & 0.697 \\
\hline & SS-7 & 2.40 & .530 & 2.45 & .552 & 2.38 & .465 & 0.442 & 0.643 \\
\hline & Total & 2.34 & .339 & 2.39 & .376 & 2.49 & .295 & 3.312 & $0.038^{*}(\mathrm{a}<\mathrm{c})$ \\
\hline
\end{tabular}

NOTE. Licence (1) Relevant qualification certificate, etc (a), (2) Industrial engineer, Engineer (b), (3) Fire equipment manager, Professional engineer $(\mathrm{c}), \mathrm{p}^{*}<.05, \mathrm{p}^{* *}<.01, \mathrm{p}^{* * *}<.001$ 
Table 11. The Group Difference of Comparison of Job Stress by Task

\begin{tabular}{|c|c|c|c|c|c|c|c|c|c|}
\hline \multirow{3}{*}{\multicolumn{2}{|c|}{ Variable }} & \multicolumn{6}{|c|}{ Task } & \multirow{3}{*}{$\mathrm{F}$} & \multirow{3}{*}{$P$} \\
\hline & & \multicolumn{2}{|c|}{ (1) } & \multicolumn{2}{|c|}{ (2) } & \multicolumn{2}{|c|}{ (3) } & & \\
\hline & & M & $\mathrm{SD}$ & M & $\mathrm{SD}$ & M & $\mathrm{SD}$ & & \\
\hline \multirow{8}{*}{$\begin{array}{c}\text { Job } \\
\text { Stress }\end{array}$} & SS-1 & $2.52^{\mathrm{a}}$ & .635 & $2.33^{\mathrm{b}}$ & .647 & $2.34^{\mathrm{c}}$ & .643 & 3.229 & $0.041 *(a>c)$ \\
\hline & $\mathrm{SS}-2$ & 2.63 & .532 & 2.59 & .484 & 2.48 & .516 & 2.837 & 0.060 \\
\hline & SS-3 & $2.57^{\mathrm{a}}$ & .580 & $2.25^{\mathrm{b}}$ & .513 & $2.38^{\mathrm{c}}$ & .658 & 7.704 & $0.001 * *(\mathrm{a}>\mathrm{c})$ \\
\hline & $\mathrm{SS}-4$ & 2.09 & .428 & 1.95 & .462 & 2.03 & .538 & 2.177 & 0.115 \\
\hline & SS-5 & $2.19^{\mathrm{a}}$ & .543 & $1.95^{\mathrm{b}}$ & .537 & $1.90^{\mathrm{c}}$ & .583 & 10.950 & $0.000 * * *(a>c)$ \\
\hline & SS-6 & 2.34 & .489 & 2.32 & .456 & 2.24 & .483 & 1.419 & 0.243 \\
\hline & SS-7 & $2.48^{\mathrm{a}}$ & .495 & $2.48^{\mathrm{b}}$ & .550 & $2.26^{\mathrm{c}}$ & .554 & 6.567 & $0.002 * *(\mathrm{a}>\mathrm{c})$ \\
\hline & Total & 2.44 & .353 & 2.35 & .352 & 2.28 & .032 & 7.065 & $0.001 * *(a>c)$ \\
\hline
\end{tabular}

NOTE. Task (1) Inspection \& check (a), (2) Safety management (b), (3) Construction, Repair \& etc. (c) $\mathrm{p}^{*}<.05, \mathrm{p}^{* *}<.01, \mathrm{p}^{* * *}<.001$

년 9월까지 총 324건의 소방시설관리사 행정처분 중 ‘점검과 다르게 기재한 사유'가 209개소(64.5\%), '실제점검 시행날짜 와 다르게 기재'가 44건(13.6\%), '관리사 미 참여'가 45건 (13.6\%), '미 점검'사유가 26건(8\%)로 나타났다. 이는 모든 책임이 관리사에게 집중되고 단순 숫자의 오기나 세부 항목 의 체크 부주의, 소방점검표 미 부착 등 경미한 사항도 공무원의 재량행위로 거짓점검 등으로 행정처분 할 수 있어 이에 대한 개선이 필요하며, 이와 같은 보고서의 과중한 책임성이 직무스트레스에 큰 영향을 줄 것이다. 또한 2020년 도에는 「화재예방 - 소방시설 설치유지 및 안전관리에 관한 법률 시행규칙」개정으로 소방시설자체점검보고서 제출기 한이 30일에서 7일로 단축됨에 따라 소방시설관리사의 업무 과중은 더욱 커질 것으로 예상된다. 이는 최종보고서를 우편 으로 관계인에게 전달하는데 걸리는 시간이 최소 2 4일을 감안하면 매우 시간이 촉박 할 것으로 판단된다. 소방시설관 리사와 관리업체에 보고서 제출 문제로 매우 큰 스트레스와 추가 비용이 부담될 것으로 전망된다.

담당업무분류에 따라 집단 간의 차이를 분석한 결과를 Table 11에서 제시하였으며, 일원배치분석결과 F값은 7.065 이고, $\mathrm{P}$ 값은 0.001 로 집단 간에 유의미한 차이가 나타났다. 표본의 크기의 불균형을 줄이고자 7 개의 집단을 3 개로 재분 류하였다. 소방점검을 그룹1로 안전관리대행업무를 그룹2 로, 보수공사 외 기타업무를 그룹3으로 세분하였다. Scheffe 사후분석 결과 '직무자율' 하위척도에서 그룹1이 그룹3보 다 크게 나타났다. 이는 그룹2와 그룹 3 의 직무가 시간에 유연하게 대처할 수 있는 반면에 소방점검그룹은 하루에 점검해야 되는 면적과 아파트 세대수가 정량화되어 있어 시간적 여유가 없는데서 기인한 것으로 판단된다. 즉, 점검 1 단위가 종합정밀점검 기준으로 1 일 점검한도 면적이 $10,000 \mathrm{~m}^{2}$ 로, 아파트의 경우는 점검한도 세대수가 300 세대 로 규정하고 있다. Shim (2011)은 자체점검 소요시간 분석에 서 점검 1 단위가 $10,000 \mathrm{~m}^{2}$ 기준을 점검할 때 소요시간이
1 일을 초과한다는 분석이 $62.5 \%$ 에 달한다고 분석하였다. 또한, Lee et al. (2009)의 연구에 따르면 소방공무원이 2인1 조로 $10,000 \mathrm{~m}^{2}$ 점검에 필요한 소요시간이 질적인 요소를 제외하더라도 2 일정도가 소요되는 것으로 보고한바 있다. 그러나 소방시설관리업에서는 보통 이 기준을 점검팀의 1 일 일정으로 하여 자체점검을 수행하도록 하기 때문에 시간적 여유가 없을 것으로 판단한다. '직무불안정'과 ‘보상 부적절'의 하위척도에서 다른 사회과학적변수에서는 볼 수 없었던 유의미한 차이를 확인하였다.

\subsection{2 사회과학적 일반적 특성에 따른 이직의도의 차이}

대상자들의 사회과학적변수에 따른 이직의도의 집단간 일원배치분석 분석 결과는 Lim and Kong (2019b)의 소방시 설관리업 종사자의 직무만족과 이직의도와의 관계 연구의 선행연구에서 제시된바 있다.

이 연구에서는 일반적 사회과학적변수에 의한 집단 간의 차이는 유의수준 0.05 수준에서 모두 차이가 없음을 알 수 있었다. 또한 주목할 점은 그룹간의 유의한 차이는 없으나 이직의도 평균값이 2.3958로 인구사회학적 변수와 관계없 이 전반적으로 이직의도가 있음을 보여주고 있다. 소방청 통계집에 의하면 6 개년 동안 종사자수는 매년 $1.5 \%$ 증가에 비하여 매출은 매년 $12 \%$ 가 넘게 성장했다는 점으로 볼 때 소방시설관리업종사자의 노동 강도가 증가하고 있는 것에 따른 영향이 미친 것으로 생각된다.

\subsection{3 직무스트레스와 이직의도 간 영향분석}

다중회귀분석을 통하여 직무스트레스와 이직의도의 영 향을 분석한 결과는 Table 12 와 같다.

전체적으로 직무스트레스는 이직의도에 정 $(+)$ 의 영향을 미치는 것으로 나타났다. 직무스트레스의 하위 척도인 '조직 체계', ‘보상부적절'에서 유의미한 결과가 나타나 연구문제 2.6과 2.7은 채택되었다. 그러나 나머지 하위척도는 유의미하 
Table 12. The Regression Analysis of Turnover Intention on Job Stress

\begin{tabular}{|c|c|c|c|c|c|c|}
\hline \multicolumn{2}{|c|}{ Variable } & SD & $\beta^{17)}$ & $t^{18)}$ & $\mathrm{p}$ & Tolerance $^{19)}$ \\
\hline \multirow{8}{*}{ T. I } & & 0.175 & & 2.509 & $0.013^{*}$ & \\
\hline & SS-1 & 0.042 & 0.050 & 1.068 & 0.286 & 0.748 \\
\hline & SS-2 & 0.053 & 0.052 & 1.065 & 0.288 & 0.688 \\
\hline & SS-3 & 0.039 & 0.004 & 0.086 & 0.931 & 0.940 \\
\hline & SS-4 & 0.057 & -0.075 & -1.591 & 0.113 & 0.744 \\
\hline & SS-5 & 0.046 & 0.015 & 0.322 & 0.747 & 0.769 \\
\hline & SS-6 & 0.067 & 0.321 & 5.650 & $0.000 * * *$ & 0.516 \\
\hline & SS-7 & 0.060 & 0.380 & 6.813 & $0.000 * * *$ & 0.536 \\
\hline
\end{tabular}

지 않아 연구문제 $2.1,2.2,2.3,2.4$ 그리고 2.5 는 기각되었다.

Song (2018)의 해석에 의하면 회귀모형은 $\mathrm{F}$ 값이 $\mathrm{p}=.000$ 에 서 36.27의 수치를 나타내고, 회귀식에 대한 수정 $\mathrm{R}^{2}=.412$ 로 $41.2 \%$ 의 설명력을 보이고 있다. Durbin-Watson은 1.866 으 로 잔차들 간의 상관관계가 없어 회귀모형이 적합하다는 것을 알 수 있었다. 추정계수에 대한 해석은 소방시설관리업 종사자의 직무스트레스 중 조직체계의 스트레스가 높아질 수록 이직의도가 $32.1 \%$ 증가하고, 보상부적절의 스트레스 가 높을수록 이직의도는 $38.0 \%$ 증가하였다. 직무스트레스 와 이직의도 간에는 직무스트레스가 높을수록 이직의도가 높아지는 $(+)$ 의 영향을 미치는 것으로 나타났다. 이 연구는 Kim (2005), Lim (2007), Ko (2008), Yun (2009), Kim (2010), Park (2016), Ko (2018), Won (2018), Bae (2019)의 연구 결과를 지지한다.14)

\section{5. 결 론}

이 연구에서는 소방시설관리업 종사자의 직무스트레스 와 이직의도에 미치는 영향을 분석하였고 요약 정리하면 다음과 같다.

(1) 사회과학적 배경원인에 따른 집단 간의 직무스트레스 는 연령, 교육수준, 월 급여에 대하여는 차이가 없었으 나, 직급, 총 경력, 자격증의 차이, 직무에 대하여는 유의미한 차이가 있었다.

(2) 직무스트레스와 이직의도의 영향을 살펴본 결과, 스 트레스가 증가함에 따라 이직의도에 정(+)의 영향을

17) 표준화계수로 독립변수가 1 만큼 증가할 때 종속변수가 얼마큼 증가 하는지를 나타낸다. 따라서 독립변수들이 종속변수에 미치는 영향 력을 의미한다.

18) 회귀분석의 결과는 $\mathrm{t}$ 값과 유의 확률 $\mathrm{p}$ 로 나타내며 $\mathrm{t}$ 값이 \pm 1.96 일 때 $\mathrm{p}$ 값은 0.05 이다. 사회과학논문에서 유의 확률기준이 $\mathrm{p}<.05$ 이므로 t값은 \pm 1.96 이상일 때 가설은 채택된다.

19) 다중회귀분석에서 독립변수끼리 높은 상관관계가 존재한다면, 다중 공선성이 발생할 가능성이 높으므로 공차한계를 기준으로 판단하였 으며, 공차한계값이 0.1 이하일 때는 다중공선성에 문제가 있다고 판단한다.
미친다. 다만, 스트레스의 하위변수 중 '조직체계'와 '보상부적절’의 스트레스가 증가함에 따라 이직의도 에 큰 영향력을 미친 반면에 ‘물리적 환경', ‘직무요구’, ‘직무자율', ‘관계갈등', ‘직무불안정'은 영향이 작음 을 알 수 있었다.

이 연구에서 스트레스 하위척도에서의 발견된 내용을 바탕으로 다음과 같이 제언하고자 한다.

(1) ‘직무요구', ‘관계갈등'에 따른 스트레스는 나이, 직 급, 임금, 경력이 많고 상위자격증소지자 일수록 높아 지는 것을 확인 할 수 있다. 이는 시간적 압박, 업무량 증가, 책임감, 과도한 직무부담과 상사와 동료 간의 전반적 지지가 원인요소이다. 따라서 전문기술서비스 용역인 업종 특징 때문에 기술인력의 직무능력 편차가 없어야 하고 직무부담정도가 고르게 부담되어야 한다. 소방시설관리사에 대한 과중한 업무를 해소 할 수 있는 시간적 배려 또는 조력이 필수적이다. 이러한 문제는 기술인력 등급관리제도의 도입과 점검보고제 도의 간소화가 필요하다. 또한 기업에서는 국가직무 능력(NCS)기반으로 하는 사내 또는 위탁교육을 통하 여 부단한 노력이 필요하다.

(2) '직무자율'에 따른 스트레스는 나이, 직급, 임금, 경력 이 적고 하위자격증소지자 일수록 높아지는 것을 확인 할 수 있다. 이는 직무에 대한 의사결정 권한과 재량활 용의 수준을 높아야 한다. 이는 한정된 범위에서라도 권한을 위임하고, 정례적인 회의와 소통 등 기업문화 적인 측면에서 배려를 확대하도록 개선책을 마련해야 할 것이다.

(3) 스트레스 하위척도 중 ‘조직체계'와 '보상부적절'에 대한 스트레스 증가는 곧바로 이직으로 연결될 수 있다. 따라서 '조직체계'의 스트레스 저감 방안은 합리 적인 경영시스템의 도입으로 체계적 조직의 정략 및 운영체계 확보, 원활한 조직지원, 합리적 의사소통의 창구를 갖추도록 해야 한다. '보상부적절'에 대한 스트 
레스 저감 방안으로는 업무에 대하여 기대하는 보상정 도가 적절하게 이루어질 수 있도록 내적동기 유발방안 마련, 기술개발과 자기계발 지원, 합리적 금전보상 기준과 적용이 필요하다.

\section{References}

Bae, S.J. (2019). The effects of occupational therapist job satisfaction and job stress on turnover and job change intention. Master's thesis, Dongshin University.

Blau, G. (1981). An empirical investigation of job stress, social support, service length, and job strain. Organizational Behavior and Human Performance, Vol. 27, No. 2, pp. 279-302.

Chae, J., Woo, S.C., and Ko, G.B. (2012). An analysis of factors affecting the job stress of firefighters. Journal of Korean Institute of Fire Science \& Engineering, Vol. 26, No. 5, pp. 28-34.

Cho, J.H. (2013). A study on the status of Korean firefighting industry and influence on the job stress of job satisfaction and worker's turnover. Master's thesis, Hanyang University.

Choi, J.G. (2015). A study on the improvement for fire safety management of fire protection object. Master's thesis, Dongshin University.

Choi, N.S., and Kim, J.G. (2011). A study on the job stress and job satisfaction of firefighters. Korean Journal of Local Government \& Administration Studies, Vol. 25, No. 3, pp. 481-501.

Jang, C.Y., and Kwon, Y.J. (2006). Moderating effect of social support on job stress: Focused on psychological burnout among teachers. Korean Society and Public Administration, Vol. 17, No. 3, pp. 157-180.

Kang, I.J. (2015). The relationships among turnover intention, career related learning, career motivation, perceived organizational support, organizational commitment, career commitment and employability of office workers in large corporations. Ph.D. dissertation, Seoul National University.

Kim, H.J. (2018). The effects of job stress and job satisfaction on turnover intention and moderating effect of organizational commitment among fire fighter. $\mathrm{Ph} . \mathrm{D}$. dissertation, Inje University.

Kim, H.S. (2005). A study on relationship of job stress, job satisfaction, organizational commitment and turnover intention of hotel employees. International Journal of Tourism Management and Sciences, Vol.
19, No. 3, pp. 203-225.

Kim, H.T. (2014). A study on improvement method of self-inspection system for fire facilities through relation analysis between fire damage and selfinspection. Master's thesis, University of Seoul.

Kim, I.S. (2010). The impact of job stress of the youth sports club instructor on job satisfaction and job turnover. Master's thesis, Kyung Hee University.

Kim, S.R. (2017). The relationship of life satisfaction and job stress for firefighters: Focus of the moderating effect of family resilience and social support. Ph.D. dissertation, Seoul Women's University.

Ko, E.J. (2018). The effects of job stress on job satisfaction, psychological burnout and turnover intention in jewelery industry worker. Master's thesis, Kyonggi University.

Ko, K.S. (2008). A study on job stress and turn over intention of employees in beauty salons. Ph.D. dissertation, Daegu Haany University.

Lee, C.W. et al. (2009). A study on the efficient task distribution and organizational operation according to the improvement of fire inspection system. Research Report, Korea Association for Organizational Studies, pp. 14-26.

Lee, H.Y., and Kim, Y.R. (2017). Effects of burnout on job stress and ego-resilience of fire officials. Fire Science and Engineering, Vol. 31, No. 2, pp. 106-112.

Lee, S.G. (2007). An empirical study on the job stress and organizational commitment of the firefighters. Ph.D. dissertation, Chung-ang University.

Lee, S.R. (2004). The effect of job stress, turnover of safeguard on job satisfaction. Ph.D. dissertation, Yonsei University.

Lim, J.H. (2007). A study on the influence of job satisfaction and job stress on turnover intention of childcare teachers. Master's thesis, University of Seoul.

Lim, K.Y., and Kong, H.S. (2019a). Effects of task stress on the job satisfaction of fire protection management workers. Fire Science and Engineering, Vol. 33, No. 5, pp. 130-139.

Lim, K.Y., and Kong, H.S. (2019b). The relationship between job satisfaction and turnover intention among fire protection system management workers. Fire Science and Engineering, Vol. 33, No. 6, pp. 142-151.

Moon, H.J. (2019). A study on improvement method of self-inspection system through the analysis of the fire safety special investigation. Master's thesis, 
University of Seoul.

Park, E.J. (2019). A study on public operating system of fire inspection. Master's thesis, Pusan National University.

Park, J.H. (2019). A study on the reliability of fire engine pump operation. Master's thesis, University of Seoul.

Park, J.S. (2016). The influence of job stress on turnover intention, public service motivation and job burnout: Focused on correctional officers. Ph.D. Dissertation, Myongji University.

Roe, K.H. (2005). A study on the causes of job-related stress of fire officers. Master's thesis, Incheon National University.

Ryu, S.I. (2013). Analysis of difference in perception on stress and job satisfaction of public servants in firefighting agency according to type of service. Journal of Korean Association for Crisis and Emergency Management, Vol. 5, No. 1, pp. 67-80.

Shim, H.A. (2010). A study on the job stress and job satisfaction of educational administration and functional civil servants in Suwon City. Master's thesis, Ajou University.
Shim, J.M. (2011). Study on the effective method of self-checking system of fire facilities. Master's thesis, University of Seoul.

Song, J.J. (2018). Statistical analysis method of the SPSS/AMOS required for Writing a thesis. Paju: 21c book.

Won, H.S. (2018). The effects of job stress and job satisfaction of professional dancers on turnover intention. Master's thesis, Sookmyung Women's University.

Yang, E.G. (2010). A study on the job stress, job satisfaction, and job turnover of office workers: Focused on the small and medium business employees. Master's thesis, Korea University.

Yun, H.M. (2009). An analysis of the factors affecting turnover intention of new nurses. Master's thesis, Pusan National University.

\begin{tabular}{|l|l|}
\hline Received & May 4, 2020 \\
\hline Revised & May 7, 2020 \\
\hline Accepted & June 24, 2020 \\
\hline
\end{tabular}

